\title{
Research on the Development of Energy Saving and Environmental Protection Industry in Jing-Jin-Ji
}

\author{
Ying-zi WANG \\ Business school, Tianjin University of Finance and Economics, Tianjin, China, 300222
}

Keywords: Beijing-Tianjin-Hebei, Integrate, Energy conservation and Environmental protection industry.

\begin{abstract}
The Beijing-Tianjin-Hebei integration has risen to the national strategy. The promotion of the integration of environmental protection in Beijing, Tianjin and Hebei is the top priority. At the same time, with the continuous changes in the economic situation at home and abroad, the environmental protection industry has become a truly sunrise industry and has become an important part of the national economy. Therefore, vigorously developing the environmental protection industry in the Beijing-Tianjin-Hebei region is an important way to meet the national strategy and promote economic development. Based on the analysis of the driving force and status quo of the environmental protection industry in the Beijing-Tianjin-Hebei region, the paper identifies the challenges facing the development of this industry in the Beijing-Tianjin-Hebei region, and then puts forward suggestions for the environmental protection industry in the Beijing-Tianjin-Hebei region.
\end{abstract}

\section{Introduction}

The Jing-Jin-Ji region is an important core area located in the Bohai Sea and even in the north. Beijing-Tianjin-Hebei includes Beijing, Tianjin and Hebei Provinces.In 2013, the total population of the Beijing-Tianjin-Hebei region was approximately 109.196 million, and the GDP of the region was approximately 6.2172 trillion yuan.

The Beijing-Tianjin-Hebei region is not only a region characterized by heavy industry, but also one of the areas with severe environmental pollution. The increasingly severe environmental pollution, especially the persistent and frequent haze, urgently demands that the Beijing-Tianjin-Hebei region effectively transform the mode of economic growth, accelerate the pace of industrial transformation and upgrading[1].

The Beijing-Tianjin-Hebei integration has been promoted as a national strategy. In the Beijing-Tianjin-Hebei integrated planning program, integration of environmental protection 、 energy resources, and public services will be the top priority. The Beijing-Tianjin-Hebei integration development attaches great importance to environmental protection, and it will inevitably have a large amount of technology, talents, funds, and government policies in its construction process.

\section{Status Quo of Energy Saving and Environmental Protection Industry in Beijing, Tianjin, Hebei}

\section{Energy Conservation and Environmental Protection Industry}

Energy-saving and environmental protection industry refers to the industry that provides technological basis and equipment guarantee for saving energy resources, developing circular economy, and protecting the environment. Including energy-saving industry, resource recycling industry and environmental protection equipment industry. Key areas for development include: environmental protection technologies and equipment, environmental protection products and environmental protection services, and resource recycling technology and equipment.

\section{Energy-Saving and Environmental Protection Industry Related Policies}

In 2014, important documents such as the "Law of the People's Republic of China on Prevention and Control of Atmospheric Pollution (Revised Draft)", "Water Pollution Prevention and Control Action 
Plan" and "Guiding Opinions on Third Party Governance of Environmental Pollution" were successively adopted[2].

\section{Energy-Saving and Environmental Protection Industry Investment}

The scale of environmental protection investment in the Beijing-Tianjin-Hebei region has increased year by year, and environmental protection investment in Hebei Province has doubled in recent years. From 2010 to 2013, Beijing, Tianjin, and Hebei provinces have seen an increase in the investment in pollution control as a result of changes in investment in industrial environmental pollution treatment, especially in Hebei Province, which rose from 2362.9 million yuan in 2012 to 5117.69 million yuan in 2013. From 2014 to 2017, Hebei province invested RMB 423.7 billion to control pollution. The funds used for air pollution control in key industries will reach more than 90 billion yuan. The annual increase in environmental protection investment will have a more significant role in the operation costs of pollution control facilities, environmental protection industries, GDP growth, and employment in the Beijing-Tianjin-Hebei region.

\section{Empirical Research}

\section{Theoretical Basis}

This section measures the trend of changes in total factor productivity of ECEP industries in the Jing-Jin-Ji region in recent years, and evaluates ECEP-industries in the Jing-Jin-Ji region from a technical perspective.

\section{Data Sources}

This paper uses the data of all ECEP-industries in the Beijing-Tianjin-Hebei region in 2009-2013, and calculates the total factor productivity of energy-saving and environmental protection industries in the Beijing-Tianjin-Hebei region using the international mainstream OP method. We remove the following observations: The key financial indicators are missing or zero. Those that do not meet the general accounting standards, including the profit rate greater than 1 , if the current assets are more than the total assets, the fixed assets are more than the total assets; the number of employees is less than $10[3]$.

\section{Outcome of Practice}

Table 1 shows the calculation results of the total factor productivity of the energy conservation and environmental protection industry of Beijing, Tianjin, Hebei in 2009-2013. It can be seen that Tianjin's industry productivity has been relatively stable in recent years, Beijing has higher total factor productivity than Tianjin and Hebei Province, and Tianjin is slightly more stable than Hebei Province's energy-saving and environmental protection industries[4].From Figure 1, it can be seen that Beijing's total factor productivity changes fluctuate greatly, which may be related to the frequent entry and exit of Beijing energy conservation and environmental protection enterprises.

Table 1. Total factor productivity of energy saving and environmental protection industry in jing-jin-ji region 2009-2013

\begin{tabular}{|c|c|c|c|c|c|}
\hline Region & 2009 & 2010 & 2011 & 2012 & 2013 \\
\hline Beijing & 1083.30 & 2513.08 & 1508.60 & 1478.39 & 2224.48 \\
\hline Tianjin & 982.64 & 1029.66 & 1001.42 & 1033.71 & 1020.05 \\
\hline Hebei & 952.13 & 1135.35 & 1091.50 & 789.37 & 999.21 \\
\hline
\end{tabular}




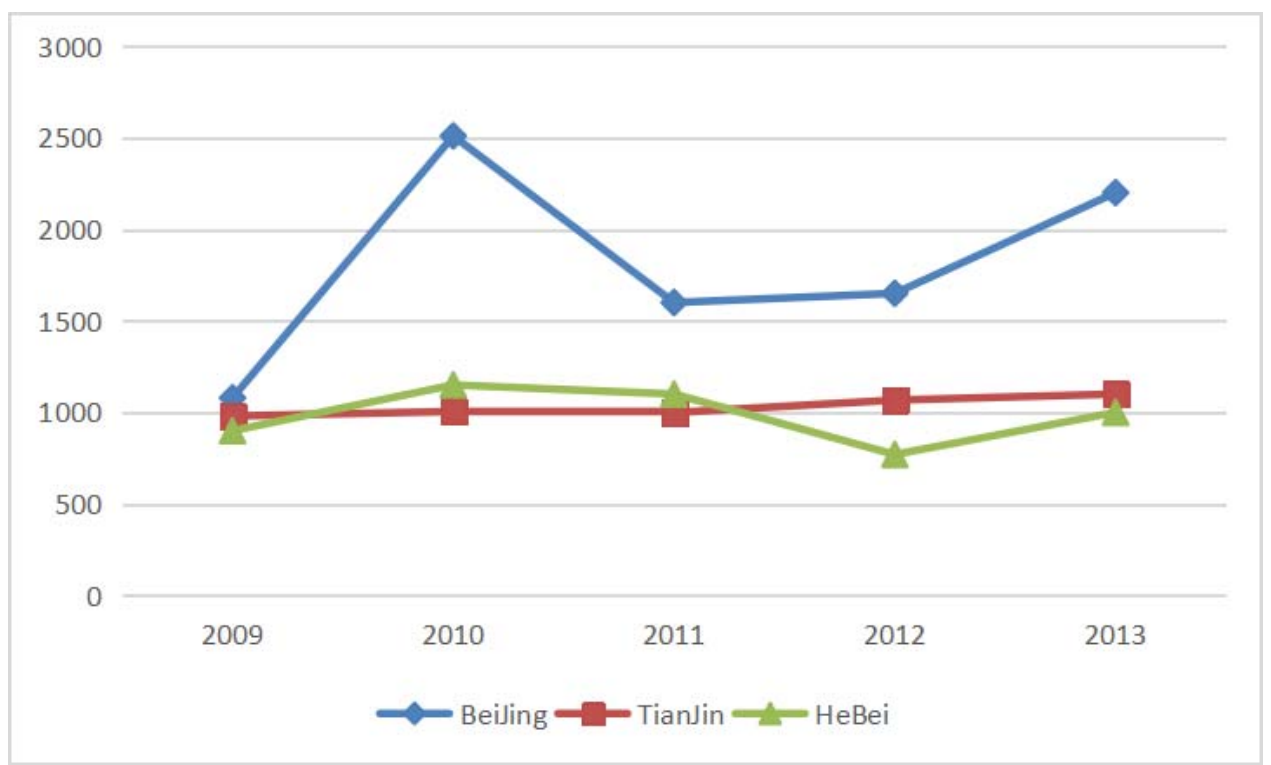

Figure 1. Energy-saving and environmental protection industry productivity trend in Beijing, Tianjin and Hebei region

\section{Problems in the Development of Environmental Protection Industry in Jing-Jin-Ji Region}

Although the Beijing-Tianjin-Hebei environmental protection industry has made great progress, it is still in its infancy and some outstanding issues need urgent study and solution.(1) The lack of understanding of the importance of developing the environmental protection industry has not yet been grasped as an important industry.(2) The industrial planning is lagging, the macro-control is ineffective, the low-level redundant construction is excessive, and the development is unbalanced.(3) The management system is not smooth, divided, multi-headed management, and lack of unified and effective guidance.

Judging from the deep-seated reasons, the low level of technology is the main reason for the lack of international competitiveness of Beijing-Tianjin-Hebei ECEP-industries. At present, China has yet to establish a sound energy-saving environmental protection technology innovation system. Some of the core technologies for energy saving and environmental protection have not been fully mastered independently, and some key equipments still need to be imported. Even if they can independently produce energy-saving and environmental protection equipment, their performance and efficiency still need to be improved. At the same time, due to factors such as the incompleteness and insufficiency of competition due to the not yet mature market economy mechanism and local protectionism[5].

\section{Countermeasures for the Development of ECEP-Industry in Jing-Jin-Ji Region}

\section{Increasing Environmental Protection Technology Innovation}

The lack of core technologies is an important reason why China's environmental protection industry is at the low end of the global environmental protection industry chain. Through the establishment of major scientific and technological special projects to promote the innovation capability of environmental protection technologies, low-carbon economy, ecological construction and other aspects of science and technology projects. We will increase the R\&D investment and policy inclinations of environmental protection technologies, make use of policies such as credit, taxation, and subsidies, and actively promote the development, demonstration, and promotion of environmental protection technologies and products. Establish a technology development model that combines production, education and research, and public-private partnerships, integrate the strengths of related research institutions, companies, and capital markets, and take concerted actions to continuously improve the company's ability to innovate and compete. In combination with its own 
characteristics, it will focus on the development of low-cost energy-saving, emission-reduction and low-carbon technologies and renewable energy technologies, and actively implement industrialization.

\section{Promoting the Development of Industrial Markets with Policy Guidance}

The market-oriented development of energy-saving industries needs policy promotion. Only by implementing policies according to local conditions can we do more with less. In the field of eco-environmental protection, a policy system focusing on support, support, and guidance should be established. While advancing the marketization of eco-environmental protection, it should fully consider the characteristics of its public welfare and externalities. In the field of production, a policy system based on binding and mandatory should be established to realize the transition from production mode to energy saving and environmental protection, supplemented by support and encouragement policies. The introduction of a price guidance mechanism will introduce the environmental costs brought about by the company's production into the company's cost accounting, and will enable the company to transform its intensive, clean, and green production methods. Advocate eco-friendly lifestyles for consumption, through price-oriented mechanisms, increase people's awareness of saving on the use of resources, and promote the use of clean energy and green products[6].

\section{Building a Good Investment and Financing Platform for the Development of ECEP-Industries}

Under the premise of following the laws of the market, some concessions can be made on the taxation aspect, to a certain extent, the uncertainty of financial institutions and energy conservation and environmental protection companies engaging in environmental financial activities can be reduced. For example, you can implement preferential treatment in both tax base and tax ratios. In terms of preferential tax bases, a certain percentage of deductions may be made for current tax payables of financial institutions engaged in environmental financial activities. In respect of the taxation rate concessions, it may try to provide certain business tax relief for financial institutions' green financial activities or may specify a business line for green finance. These two kinds of tax incentives have their own characteristics and advantages and disadvantages. In specific operations, they can be combined organically to form a powerful combination of tax revenue.

\section{References}

[1] Huang Qingzi, Wang Zhenzhen, Wang Lijian, Comparative Analysis of China's Environmental Protection Industry Policy Tools: An Empirical Study Based on GRA-VAR Model[J]. Resources, 10 (2016) 1988-2000.

[2] Guo Jianqing, Li Menggang, Difficulties in China's Energy Conservation and Environmental Protection Industry Development and Breakthrough Strategies[J]. Economic Review, 06 (2016) 52-56.

[3] Tao Jin. Research on the Influencing Factors of Energy Conservation and Environmental Protection Industry in China[D]. Anhui University of Finance and Economics, 2015.

[4] Jiang Guo. Research on the construction of energy-saving and environmental protection industrial chain in Jing-Jin-Ji[D]. Hebei University of Economics and Business, 2015.

[5] Zeng Shihong, Li Meng, Research on the Credit Risk of Listed Companies in Energy Conservation, Environmental Protection and New Energy Industries Based on KMV method[J]. China Polulation. Resources and Environment, 24(2014), 54-57.

[6] Niu Guimin. Analysis of the Development of Energy Conservation and Environmental Protection Industry in China[J]. Journal of Theoretical Research, 05(2014), 43-47. 